\title{
Predictive validity of 4 risk assessment scales for prediction of pressure ulcer development in a hospital setting
}

Ulrika Källman and Margareta Lindgren

\section{Linköping University Post Print}

\section{Tweet}

N.B.: When citing this work, cite the original article.

Original Publication:

Ulrika Källman and Margareta Lindgren, Predictive validity of 4 risk assessment scales for prediction of pressure ulcer development in a hospital setting, 2014, Advances in Skin \& Wound Care, (27), 2, 70-76.

http://dx.doi.org/10.1097/01.ASW.0000439059.72199.41

Copyright: Lippincott, Williams \& Wilkins

http://www.lww.com/

Postprint available at: Linköping University Electronic Press

http://urn.kb.se/resolve?urn=urn:nbn:se:liu:diva-104219 


\section{Predictive Validity of 4 Risk} Assessment Scales for Prediction of Pressure Ulcer Development in a Hospital Setting

Ulrika Källman, RN, PhD student; and Margareta Lindgren, RN, PhD, Ass. professor

Ulrika Källman, RN is a PhD student and at the Department of Medicine and Health, Faculty of Health Sciences, Linköping University, Linköping, Sweden and RN at the Department of Dermatology, Södra Älsvorgs Hospital, Borås Sweden. Margareta Lindgren RN, PhD, is an Ass.Professor, Department of Department of Medicine and Health, Faculty of Health Sciences, Linköping University.

Acknowledgments: The authors thank the study participants for their patience and cooperation and also the partnering organizations and their senior nurse leaders and staff for all the help given during the research project. Additional thanks are extended to Södra Älvsborg Hospital, Borås, and Linköping University, Linköping, Sweden. The authors have disclosed that they have no financial relationships related to this article. Submitted October 12, 2012; accepted in revised form March $8,2013$.

\section{ABSTRACT}

OBJECTIVES: The aims of this study were to examine and compare the predictive validity of 4 risk assessment scales used for the prediction of pressure ulcer (PrU) development and to identify risk factors.

DESIGN: Cross-sectional descriptive study.

SETTING: A general hospital in Sweden.

PARTICIPANTS: Patients (all aged $\geq 18$ years) admitted to medical, surgical, orthopedic, oncology, and rehabilitation wards. Of 412 patients available, a total of 346 patients participated in the study.

METHOD: Data were collected using the Swedish version of the European Pressure Ulcer Advisory Panel minimum data set as well as the Norton, Modified Norton, Braden, and RAPS (Risk Assessment Pressure Ulcer Scale) scales. The predicative validity was estimated by measuring sensitivity, specificity, positive predictive value, and negative predictive value. Multiple logistic regression analysis was used to determine risk factors associated with PrUs. 
[Skriv text]

RESULTS: The RAPS scale reached best balance between sensitivity and specificity at the recommended cutoff level of less than or equal to 29 , followed by the Braden scale and the Norton scale at recommended cutoff levels less than or equal to 18 versus less than or equal to 16 , respectively. The modified Norton scale also reached an acceptable balance between sensitivity and specificity but at the cutoff level of less than or equal to 23 , which is a higher cutoff level than recommended. General physical condition, physical activity, moisture, friction, and shear emerged as significant risk factors.

CONCLUSIONS: The results support that the recommended cutoff levels of the RAPS, Norton and Braden, and are valid in a general hospital setting. However, the recommended cutoff level of the modified Norton scale $(\leq 20)$ has to be increased when used in this care context.

Pressure ulcer (PrU) development constitutes a major problem in nursing care and causes pain and suffering to those who are affected. Not only do PrUs jeopardize the health of patients, but also they are associated with significant costs in healthcare. In Sweden, the prevalence of PrUs has been shown to be $14 \%$ to $27 \%$ among hospital inpatients, ${ }^{1,2}$ and the incidence stands at $11.5 \%$ to $28 \% .{ }^{3,4}$ Among hospital inpatients in other European countries, $4.5 \%$ to $18 \%$ prevalence of PrUs has been found, ${ }^{5,6}$ and in the United States, $6.3 \%$ to $20 \%{ }^{2,7,8}$ The prevention of pressure ulcer formation is an important aspect of nursing care, and the identification of patients who require preventive measures is a key issue. One recommendation to facilitate the identification process is to perform 
[Skriv text]

systematic risk assessments using a risk assessment scale that has been tested for validity and reliability in addition to clinical judgement. ${ }^{9}$ Various risk assessment scales have been developed since the early 1960s, and all of the scales have claimed to have acceptable ability to identify patients at risk of pressure ulcer development. However, changes in hospital care such as the prevalence of an older patient population and shorter hospital stay motivate continuous and repeated examination of the predictive validity of these instruments.

\section{LITERATURE REVIEW}

According to the European Pressure Ulcer Advisory Panel (EPUAP) and the National Pressure Ulcer Advisory Panel, ${ }^{9}$ a PrU is defined as "localized injury to the skin and/or underlying tissue usually located over bony prominences, as a result of pressure or pressure in combination with shear."

Other extrinsic factors such as heat accumulation between the patient and the bed, friction, irritants, and poor hygiene are among other important contributing factors. ${ }^{10,11}$

Furthermore, there are numerous intrinsic factors that affect the ability of the patient's skin to resist pressure and shear forces, where age, nutrition, level of mobility and activity, body temperature, incontinence (moisture), peripheral vascular disease, blood pressure, serum albumin, general physical 


\section{[Skriv text]}

condition, sensory perception, and skin condition have been shown to be of significance. ${ }^{12-16}$

A risk assessment scale summarizes a range of these intrinsic and extrinsic factors; however, as a scale should be easy to use, it is not possible to include all factors. It is important that the instruments include the most important risk factors and have the ability to correctly identify patients at risk. ${ }^{17,18}$ This designates as the instrument's sensitivity and specificity and predictive value. A risk assessment scale should have high sensitivity so as to be able to correctly identify as many patients as possible as positive (ie, those who are at risk of pressure ulcer development). It should also have high specificity so as to be able to correctly identify as many patients as possible as negative (ie, those who are not at risk of pressure ulcer development). Likewise, the positive (PPV) and negative predictive values (NPV) should be high. Positive predictive value is defined as the probability of pressure ulcer development among those who are classified as risk patients. Negative predicative value is defined as the probability of not developing PrUs among those who are defined as not being at risk. ${ }^{19}$

However, to have a test that is both highly sensitive and highly specific is usually not possible. Instead, a cutoff level, based on a decision as to where the best balance 
[Skriv text]

between the sensitivity and specificity is found, is often used. ${ }^{18}$

\section{The Norton Scale}

The Norton scale was one of the first risk assessment scales developed to predict pressure ulcer development. It was based on clinical experience of a geriatric population in the early $1960 \mathrm{~s}^{20}$ and includes 5 variables (Table 1 ). The variables are divided into 4 subcategories, each with a score range of 1 (very bad) to 4 (good), giving a maximum score of 20 . The total score is related to a cutoff level, indicating the presence or absence of risk of pressure ulcer development. When first introduced, a cutoff level of less than or equal to 14 was suggested for patients "at risk." The author later reconsidered and suggested that a cutoff level of 15 or 16 should be used instead, because of changes in care over time. ${ }^{21}$ Table 2 gives an overview of previous research into the predictive validity of the Norton scale with different cutoff levels and different settings used.

\section{The Modified Norton Scale}

A modified version of the Norton scale was first used in Sweden in 1987 by Ek. ${ }^{22}$ The scale adds the variables food and fluid intake, body temperature, and social activity onto the original Norton scale. The scale was again modified after a multiple regression analysis. ${ }^{23}$ Body temperature and social 
[Skriv text]

activity were excluded from the scale as they did not appear to be specific risk factors, but the variables food and fluid intake were retained (Table 1 ). This remodified version has a maximum score of 28. Patients with a total score of less than or equal to 21 are considered to be at risk of developing PrUs, ${ }^{23}$ whereas a cutoff level of less than or equal to 20 is recommended in the Swedish Handbook for Healthcare. ${ }^{24}$ The modified Norton scale has been validated in long-term care and orthopedic settings (Table 2).

\section{The Braden Scale}

The Braden scale was developed in the late $1980 \mathrm{~s}$ and is based on an overview of literature on the subject. ${ }^{25}$ The scale consists of 6 variables: activity, mobility, nutritional status, sensory perception, moisture, and friction and shear (Table 1 ). Each variable is rated 1 to 4 , except for the friction and shear variable, which is rated from 1 to 3, thus generating a maximum score of 23. The cutoff level was originally reported as less than or equal to 16, but further testing has resulted in a recommended cutoff level of less than or equal to $18 .{ }^{26,27}$ Study results of the predictive validity for the Braden scale are presented in Table 2 .

\section{The RAPS Scale}

Lindgren et $\mathrm{al}^{3}$ introduced the RAPS scale (Risk Assessment Pressure Ulcer Scale) in Sweden in the early 2000s. The scale 
[Skriv text]

consists of variables culled from the Norton, modified Norton, and Braden scales. The final version of the RAPS scale is composed of the following variables: general physical condition, activity, mobility, moisture, food intake, fluid intake, sensory perception, friction and shear, body temperature, and s-albumin (Table 1). The maximum score is 39 , and a cutoff level of less than or equal to 31 has been suggested (Table 2). However, as s-albumin is not always available, a version without this variable is often used. The maximum score is then 35 with a recommended cutoff level of less than or equal to $29 .{ }^{28}$

The aim of this study was to determine the predictive validity of these 4 risk assessment scales in a Swedish hospital setting. Two of the scales are commonly used in Sweden (modified Norton and RAPS), and 2 are used worldwide (Norton and Braden scales). A secondary aim was also to identify risk factors for pressure ulcer development.

\section{METHODS}

\section{Setting and Sample}

This cross-sectional descriptive study was conducted in a hospital in southern Sweden. At the time of the study, the hospital had 510 beds divided into 36 departments.

After receiving approval from the hospital management to implement the study, one of the researchers identified teams 


\section{[Skriv text]}

of nurses to perform the data collection on each ward. Each team consisted of 2 nurses: 1 registered nurse from the ward being surveyed and 1 registered nurse or assistant nurse from another ward who was an expert in the field of PrUs. Prior to the study, all teams were educated in the use of the data collection instrument, how to perform the risk assessment, and how to define PrUs according to the EPUAP classification. ${ }^{9}$

The data collection was performed between 7 AM and 4 PM during the course of 1 day in November 2009. Patients older than 18 years and who were admitted to the medical, surgical, orthopedic, oncology, or rehabilitation ward were included in the study. Patients who were treated in the children's ward, psychiatric wards, outpatient clinics, day care, and maternity ward were excluded from the study.

Registered nurses at each ward informed the patients or relatives, both orally and in writing, about the study on the day prior to the survey. All patients were guaranteed confidentiality and were assured that no individuals could be identified when results were published. After obtaining the patients' informed consent or, for unconscious patients, the consent of the next of kin, each patient was thoroughly examined for the presence or absence of PrUs by the 2 nurses on the day of the survey. The nursing teams also completed a 
[Skriv text]

data collection protocol on all patients, including background data such as gender, age, and date of admission.

An ethical application was sent to the regional ethical committee, and the board gave an advisory opinion (Dnr 58207), which was subsequently followed. The study has also been performed in accordance to the Declaration of Helsinki.

\section{Data Collection Protocol}

The protocol used for the data collection was based on the Swedish version of the EPUAP-minimal data set. ${ }^{29}$ It consists of the following categories: general data, patient data, risk assessment, incontinence (modified), skin observation, preventive measures, and reason for eventual exclusion. Some new items regarding documentation were added to the categories as well as a tick box for informed consent. Observed PrUs were classified in accordance to the EPUAP classification system: category 1 pressure ulcer being a non-blanchable erythema, category 2 being an abrasion or blister, category 3 being a superficial ulcer, and category 4 being a deep ulcer. ${ }^{9}$ The location of existing PrUs was marked on a body map, and the most dominant pressure ulcer was also noted according to the following response alternatives: sacrum, heel, hip, or "other." 
[Skriv text]

The risk of each patient developing PrUs was assessed using the 4 aforementioned risk assessment scales. The RAPS scale used in this study was the version without s-albumin.

The variables from the scales were put together in 1 document. Two of the included variables' subscales differ from the others, those being food intake/nutritional status and moisture/incontinence. In the mutual scale, the definition from the RAPS and modified Norton scale regarding food intake was chosen. Likewise, the description from the RAPS and the Braden scale regarding moisture was used. The kinds of incontinence aids (urinary and/or fecal) and urinary catheter used were also noted if relevant.

\section{Statistical Analysis}

Nonparametric data are presented as frequencies and percentages, and parametric data are presented as means and SD. Comparisons were made between patients with PrUs and patients without. The predicative validity was estimated by measuring sensitivity, specificity, PPV, and NPV; all of these are presented as percentages. Figure 1 shows the relationship between the risk assessment scale and the presence or absence of PrUs. The sensitivity was calculated as a / $(a+c)$, specificity as $d /(b+d), \operatorname{PPV}$ as $a /(a+b)$, and NPV $d /(c$ + d) ${ }^{19}$ The values change depending on how the different cutoff levels of the scales identify patients as "at risk" or "not at 
[Skriv text]

risk." To define the prognostic validity of the scales, the area under curve was calculated. Multiple logistic regression analysis was used to determine factors associated with PrUs. The dependent variable, the presence of PrUs, was coded as 0 representing no pressure ulcer and 1 representing presence of PrUs. All the factors in the assessment scales were used as covariates (Table 2).

\section{RESULTS}

\section{Participants}

On the day of the survey, 412 patients were available for inclusion. However, 12 patients declined participation, 29 were not available for participation at the time of survey, and 25 patients did not participate for other reasons. Thus, 346 patients were included in the study. The mean age of the participants was 71 (SD, 16.2) years, and 172 (49.9\%) of the patients were female.

Fifty-six of the 346 patients were found to have at least

1 pressure ulcer, yielding a prevalence rate of $16.2 \%$. Of these patients, 23 (41.5\%) had category 1 ulcers, 2 (19.5\%) had ulcers of category 2, 11 (19.5\%) of category 3, and 11 (19.5\%) of category 4. The 56 patients with PrUs experienced a total of 83 PrUs. Heels $(\mathrm{n}=21$ [37.5\%]) and the sacrum $(\mathrm{n}=$ 14 [25\%]) were the most frequent sites of the patients' most severe pressure ulcer. Twenty-eight percent ( $\mathrm{n}=97$ ) of all 
[Skriv text]

participating patients received some kind of pressure ulcer preventive measure (mattresses/cushions in bed or chair and/or regularly repositioning in bed or chair), of whom $34 \%$ ( $\mathrm{n}=33$ ) had a pressure ulcer. Further characteristics of the participants are presented in Table 3 .

\section{Predictive Validity of Risk Assessment Scales}

The results of the predictive validity screening tests of the Norton, modified Norton, Braden, and RAPS scales are summarized in Table 4. The RAPS scale showed the best balance between sensitivity (77.8\%) and specificity (69.9\%) at the recommended cutoff level $(\leq 29)$, followed by the Braden scale (sensitivity $74.5 \%$ and specificity $73.7 \%$ ) at the recommended cutoff level of less than or equal to 18, and the Norton scale (sensitivity $74.5 \%$ and specificity $70.6 \%$ ) at the recommended cutoff level of less than or equal to 16 . The best balance between sensitivity (77.8\%) and specificity (68.4\%) of the modified Norton scale was reached at a cutoff level of less than or equal to 23. Acceptable area under curve was reached for all scales (Table 4).

At these cutoff levels, which show the best balance between sensitivity and specificity, the modified Norton scale had the highest PPV (35.1\%), and the RAPS scale the highest NPV (94.4\%); the Norton scale had both the lowest PPV (32.5\%) and $\operatorname{NPV}(93.6 \%)$ 
[Skriv text]

When performing a multiple logistic regression analysis including all variables in the different risk assessment scales, the following variables emerged as significant risk factors for pressure ulcer development: general physical condition $(P>.001)$, physical activity $(P=.029)$, friction and shear $(P=.036)$, and moisture $(P=.041)$.

\section{DISCUSSION}

This study aimed to examine and compare the predictive validity of the 4 different risk assessment scales used for the prediction of pressure ulcer development in a hospital setting. These scales were the Norton, modified Norton, Braden, and the RAPS scale. All the scales achieved acceptable prognostic validity, sensitivity, specificity, and NPV, but the scales' PPVs were low. The result both supports and contradicts previously recommended cutoff levels.

Concerning the 2 risk assessment scales commonly used in Sweden (the modified Norton scale and the RAPS scale), comparison with previous research is not easily done. Regarding the RAPS scale version without the risk factor salbumin, a cutoff level of 29 has been recommended. ${ }^{28}$ The findings in this study support that this estimation is suitable in a hospital setting. One can argue that a better balance between sensitivity and specificity was received at a cutoff level of 28 for the RAPS scale. However, it is 


\section{[Skriv text]}

preferable to choose a cutoff level generating higher sensitivity than specificity when it is important not to miss the presence of disease or, in this case, the risk of an injury such as a pressure ulcer. ${ }^{18}$

The modified Norton scale has previously been validated within long-term care and for orthopedic patients, but not in a general hospital setting. In previous research, a cutoff level of 21 has been used, but in the Swedish Handbook for Healthcare, ${ }^{24}$ a cutoff level of 20 is recommended. Based on the reasoning that higher sensitivity is preferable to higher specificity, this study indicates that the cutoff level should be as high as 23. ${ }^{18}$ These study results could be used as a basis for discussion concerning the current recommended cutoff level and if it should be reconsidered.

The discrepancies in the sensitivity between the modified Norton and the RAPS scale, as they are used in practice, are interesting and may have repercussions for the care provided. The risk assessment's aim is to function as a guide to identify which patients are in need of preventive measures. As the sensitivity for the modified Norton scale was $59.6 \%$ at the recommended cutoff score of 20, fewer patients will be identified as "at risk" at hospitals using this scale than at hospitals using the RAPS scale (with a sensitivity of 77.8\%). That means that if nurses in Sweden make the decision as to 


\section{[Skriv text]}

whether to deliver preventive measures based on the results of the risk assessment scale, nursing care will not be equal. Hypothetically, fewer patients will achieve preventive measures at hospitals using the modified Norton scale than patients at hospitals using the RAPS scale.

The author of the Norton scale has suggested raising the cutoff level from 14 to 15 or $16 .{ }^{30}$ The results of this study, as well as those in the study by Balzer et al, ${ }^{5}$ support a cutoff level of 16 being used in hospital settings.

Findings were similar for the Braden scale; further testing by the authors and others have resulted in a recommendation of a cutoff level of 18 instead of $16,{ }^{27}$ which is also supported by our results. However, researchers Balzer et $a l^{5}$ and Halfens et $a l^{31}$ find the best balance to be at an even higher cutoff level: 19 or 20 in a hospital setting. It is desirable to have a risk assessment scale that is both highly sensitive and highly specific. However, there is an important difference between a diagnostic screening test and a risk assessment scale. The use of effective pressure ulcer preventive measures will alter the validity test of the risk assessment scales. ${ }^{32}$ For example, if a highly sensitive risk assessment scale is used and preventive measures are effective, both the sensitivity and specificity will decrease. For this reason, sensitivity and specificity criteria have 


\section{[Skriv text]}

been criticized for not being the most appropriate tools to validate risk assessment scales. ${ }^{33}$ Because of it being ethically unacceptable to withhold preventive measures, a lower level of sensitivity and specificity has to be accepted. The effect of preventive measures could also be the reason why the PPV of the scales was not very high, irrespective of the cutoff level used. A further explanation could also be due to the fact that patients' health improved during their hospital stay, and because of this they did not develop PrUs. The interpretation of a positive or negative diagnostic test result varies from setting to setting, according to the prevalence of disease, or, in this case injury, in the particular setting. If the prevalence in this study had been higher, it is likely that the PPV would have been higher and NPV lower. ${ }^{19}$

A further aim of this study was to identify risk factors for pressure ulcer development. In the multiple regression analysis, the variables general physical condition, physical activity, friction and shear, and moisture emerged as significant risk factors for pressure ulcer development. It was somewhat surprising that immobility did not emerge as a significant risk factor as previous studies have shown that this risk factor is strongly associated with the development of PrUs. ${ }^{12,13}$ However, the variable of friction/shear has shown 
[Skriv text]

to be highly correlated with immobility ${ }^{13}$ and could thus have diminished the effect of immobility. Furthermore, as the variables of physical activity and immobility almost elucidate the same thing, it is possible that these risk factors (variables) are correlated to each other as well.

It is of primary importance that the instruments include significant risk factors and have the ability to accurately identify patients at risk of pressure ulcer development. Based on the risk assessment scales validated in this study, the RAPS scale was the only instrument including all the risk factors that emerged as significant in this study.

\section{STUDY LIMITATIONS}

A possible problem with this study is that the variables from the different assessment scales have been merged and not tested for reliability and validity as a whole scale. However, each scale has been tested separately, and several of the variables are the same in the different scales. The strength of this study may be that the risk assessment scales have been validated using the same sample and under the same conditions.

To further test the predictive validity of the risk assessment scales included in the study, a prospective design may be used. This was not possible in the current study; furthermore, a prospective study may see preventive measures that interfere with the results. 
[Skriv text]

\section{CONCLUSIONS}

The result supports that the recommended cutoff levels of the

Norton (level $\leq 16)$, Braden (level $\leq 18)$, and RAPS scales

(level $\leq$ 29) are valid for achieving good balance between

sensitivity and specificity in hospital settings. However, the

recommended cutoff level of the modified Norton scale (level

$\leq 20)$ must be increased when used in a hospital setting.

\section{References}

1. Wann-Hansson C, Hagell P, Willman A. Risk factors and prevention among patients with hospital-acquired and pre-existing pressure ulcers in an acute care hospital. J Clin Nurs 2008;17:1718-27.

2. Gunningberg L, Donaldson N, Aydin C, et al. Exploring variation in pressure ulcer prevalence in Sweden and the USA: benchmarking in action. J Eval Clin Pract 2012;18:904-10.

3. Lindgren M, Unosson M, Krantz AM, et al. A risk assessment scale for the prediction of pressure sore development: reliability and validity. J Adv Nurs 2002;38:190-9.

4. Gunnarsson AK, Lonn K, Gunningberg L. Does nutritional intervention for patients with hip fractures reduce postoperative complications and improve rehabilitation? J Clin Nurs 2009;18:1325-33.

5. Balzer K, Pohl C, Dassen T, et al. The Norton, Waterlow, Braden, and Care Dependency Scales: comparing their validity when identifying patients' pressure sore risk. J Wound Ostomy Continence Nurs 2007;34:389-98.

6. Vanderwee K, Clark M, Dealey C, et al. Pressure ulcer prevalence in Europe: a pilot study. J Eval Clin Pract 2007; 13:227-35.

7. Vangilder C, MacFarlane GD, Meyer S. Feature: results of nine international pressure ulcer prevalence surveys: 1989 to 2005. Ostomy Wound Manage 2008;54:40-54.

8. Jenkins ML, O'Neal E. Pressure ulcer prevalence and incidence in acute care. Adv Skin Wound Care 2010;23:556-9.

9. EPUAP/NPUAP. European Pressure Ulcer Advisory Panel and National Pressure Ulcer Advisory Panel— Prevention and Treatment of Pressure Ulcers: Quick Reference Guide. Washington, DC: National Pressure Ulcer Advisory Panel; 2009:22. 
[Skriv text]

10. Bridel J. The epidemiology of pressure sores. Nurs Stand 1993;7:25-30.

11. Orsted H, Ohura T, Harding K. Pressure, Shear, Friction and Microclimate in Context . A consensus document.. Wounds International, London, UK; 2010.

12. Lyne PA, Papanikolaou P, Lycett E. An empirical investigation of pressure ulcer risk factors. Nurs Stand 2000;14:46-8, 50, 53.

13. Lindgren M, Unosson M, Fredrikson M, et al. Immobility - a major risk factor for development of pressure ulcers among adult hospitalized patients: a prospective study. Scand J Caring Sci 2004;18:57-64.

14. Defloor T, Grypdonck MF. Pressure ulcers: validation of two risk assessment scales. J Clin Nurs 2005;14:373-82.

15. Fogerty M, Abumrad N, Nanney L, et al. Risk factors for pressure ulcers in acute care hospitals. Wound Repair Regen 2008;16:11-8.

16. Moore Z, Cowman S. Pressure ulcer prevalence and prevention practices in care of the older person in the Republic of Ireland. J Clin Nurs 2012;21:362-71.

17. Flanagan M. Who is at risk of a pressure sore? A practical review of risk assessment systems. Prof Nurse $1995 ; 10: 305-8$.

18. Fletcher R, Fletcher S. Clinical Epidemiology—The Essentials. 4th ed. Philadelphia, PA: Lippincott Williams \& Wilkins; 2005.

19. Altman D. Practical statistics for medical research. London, UK: Chapman \& Hall; 1999.

20. Norton D, McLaren R, Exton-Smith AN. An Investigation of Geriatric Nursing Problems in Hospital. 3rd ed. London, UK: Churchill Livingstone; 1979.

21. Norton D. Calculating the risk: reflections on the Norton scale. Decubitus 1989;2:24-31.

22. Ek AC. Prediction of pressure sore development. Scand J Caring Sci 1987;1:77-84.

23. Ek AC, Bjurulf P. Interrater variability in a modified Norton scale. Scand J Caring Sci 1987;1:99-102.

24. Healthcare HF. Modifierad Nortonskala [Trycksår]. Stockholm, Sweden: Inera AB; 2011.

25. Braden B, Bergstrom N. Predictive validity of the Braden scale for pressure sore risk in a nursing home population. Res Nurs Health 1994;17:459-70.

26. Braden B, Bergstrom N. A conceptual schema for the study of the etiology of pressure sores. Rehabil Nurs 1987;12:8-12. 
[Skriv text]

27. Ayello EA, Braden B. How and why to do pressure ulcer risk assessment. Adv Skin Wound Care 2002;15:125-31; quiz 132-3.

28. Lindgren M. Quality indicators for patients with or at risk of pressure ulcers. In: Idwall E, ed. Quality Indicators for: Pain, Oral Health, Nutrition and Pressure Ulcers. Linköping, Sweden: Department of Medicine and Care, Nursing Science, Linköping University; 2005.

29. Gunningberg L, Carlsson S, Willman A. EPUAP-protocol—a European method to survey pressure ulcers. Vård i norden 2006;26:48-51(in Swedish)

30. Norton D. Calculating the risk: reflections on the Norton scale. 1989. Adv Wound Care 1996;9:38-42.

31. Halfens RJ, van Achterberg T, Bal RM. Validity and reliability of the Braden scale and the influence of other risk factors: a multi-centre prospective study. Int J Nurs Stud 2000;37:313-9.

32. de Laat E. Critical Pressure - pressure ulcer care in critically ill patients and hospitalised patients at large [thesis]. Nijmegen, the Netherlands: Radboud University; 2006.

33. Defloor T, Grypdonck MF. Validation of pressure ulcer risk assessment scales: a critique. J Adv Nurs 2004;48:613-21.

34. Ek AC, Unosson M, Larsson J, Von Schenck H, Bjurulf P. The development and healing of pressure sores related to the nutritional state. Clin Nutr. 1991;10(5):245-50.35.

35. Goldstone L, Goldstone J. The Norton score: an early warning of pressure sores? J Adv Nurs 1982;7:419-26. 36. Pang SM, Wong TK. Predicting pressure sore risk with the Norton, Braden, and Waterlow scales in a Hong Kong rehabilitation hospital. Nurs Res 1998;47:147-53.

37. Schoonhoven L, Haalboom JRE, Bousema MT, et al. Prospective cohort study of routine use of risk assessment scales for prediction of pressure ulcers. BMJ 2002;325:1-5.

38. Jalali R, Rezaie M. Predicting pressure ulcer risk: comparing the predictive validity of 4 scales. Adv Skin Wound Care 2005;18:92-7.

39. Gunningberg L. Implementation of risk assessment and classification of pressure ulcers as quality indicators for patients with hip fractures. J Clin Nurs 1999;8:396-406.

40. Bergstrom N, Braden BJ, Laguzza A, et al. The Braden scale for predicting pressure sore risk. Nurs Res 1987;36:205-10. 
[Skriv text]

41. Bergstrom N, Braden B, Kemp M, et al. Predicting pressure ulcer risk: a multisite study of the predictive validity of the Braden scale. Nurs Res 1998;47:261-9.

42. Tannen A, Balzer K, Kottner J, et al. Diagnostic accuracy of two pressure ulcer risk scales and a generic nursing assessment tool. A psychometric comparison. J Clin Nurs;19:1510-8. 
Table 1. Describes the variables included in the Norton scale, modified Norton scale, Braden scale and RAPS scale, and their point range in each variable and the scales maximum score

\begin{tabular}{|c|c|c|c|c|c|}
\hline Variable & $\begin{array}{l}\text { Variable point } \\
\text { range }\end{array}$ & $\begin{array}{c}\text { The Norton } \\
\text { scale }^{\text {a }}\end{array}$ & $\begin{array}{l}\text { The modified } \\
\text { Norton scale }^{\text {b }}\end{array}$ & $\begin{array}{l}\text { The Braden } \\
\text { scale }^{c}\end{array}$ & $\begin{array}{l}\text { The RAPS } \\
\text { scale }^{\text {d }}\end{array}$ \\
\hline General physical condition & $1-4$ & $\mathrm{X}$ & $\mathrm{X}$ & & $\mathrm{X}$ \\
\hline Mental state & $1-4$ & $\mathrm{X}$ & $\mathrm{X}$ & & \\
\hline Activity & $1-4$ & $\mathrm{X}$ & $\mathrm{X}$ & $\mathrm{X}$ & $\mathrm{X}$ \\
\hline Mobility & $1-4$ & $\mathrm{X}$ & $\mathrm{X}$ & $X$ & $X$ \\
\hline Food intake/nutritional status & $1-4$ & & $\mathrm{X}$ & $\mathrm{X}$ & $X$ \\
\hline Fluid intake & $1-4$ & & $\mathrm{X}$ & & $\mathrm{X}$ \\
\hline Sensory perception & $1-4$ & & & $\mathrm{X}$ & $\mathrm{X}$ \\
\hline Friction and shear & $1-3$ & & & $\mathrm{X}$ & $\mathrm{X}$ \\
\hline Moisture/Incontinence & $1-4$ & $\mathrm{X}$ & $\mathrm{X}$ & $\mathrm{X}$ & $\mathrm{X}$ \\
\hline Body temperature & $1-4$ & & & & $\mathrm{X}$ \\
\hline S-albumin & $1-4$ & & & & $(\mathrm{X})$ \\
\hline Maximum score & & 20 & 28 & 23 & $39 / 35$ \\
\hline
\end{tabular}

${ }^{\mathrm{a}}$ Norton et al. (1979); ${ }^{\mathrm{b}}$ Ek et al. (1991); ${ }^{\mathrm{c}}$ Braden \& Bergstrom (1987); ${ }^{\mathrm{d}}$ Lindgren et al. (2002) (39p with Salbumin, $35 \mathrm{p}$ without $\mathrm{S}$-albumin) 
Table 2. Summary of a selection of previous studies regarding the Norton, modified Norton, Braden and the RAPS scales with presentation of the; number of participants (n), clinical setting, the Area under the curve (AUC) value, cut-off level with best balance between sensitivity and specificity, positive predictive value (PVP) and negative predictive value (NPV) and the incidence or prevalence that the figures are based on. The reference list number is present after each reference.

\begin{tabular}{|c|c|c|c|c|c|c|c|c|c|}
\hline Scale /Reference & n & $\begin{array}{l}\text { Clinical } \\
\text { setting }\end{array}$ & $\mathbf{A U C}$ & $\begin{array}{l}\text { Cut-off } \\
\text { score }\end{array}$ & $\begin{array}{l}\text { Sensiti } \\
\text {-vity }(\%)\end{array}$ & $\begin{array}{l}\text { Specifi } \\
\text {-city } \\
(\%)\end{array}$ & $\begin{array}{l}\text { PVP } \\
(\%)\end{array}$ & $\begin{array}{l}\text { NPV } \\
(\%)\end{array}$ & $\begin{array}{l}\text { Incidence }^{\mathrm{a}} \text { or } \\
\text { prevalence }^{\mathrm{b}}(\%)\end{array}$ \\
\hline \multicolumn{10}{|l|}{ The Norton scale } \\
\hline $\begin{array}{l}\text { Goldstone \& } \\
\text { Goldstone } 1982^{1}\end{array}$ & 40 & Orthopaedic & - & $\leq 14$ & 89 & 64 & - & - & $45^{\mathrm{a}}$ \\
\hline Pang \& Wong $1998^{2}$ & 106 & $\begin{array}{l}\text { Medical- } \\
\text { Orthopaedic }\end{array}$ & - & $\leq 16$ & 81 & 59 & 33 & 93 & $20^{\mathrm{a}}$ \\
\hline $\begin{array}{l}\text { Schoonhoven et al. } \\
2002^{3}\end{array}$ & 2190 & Hospital & 0.56 & $\leq 15$ & 46 & 60 & 7 & 94 & $11^{\mathrm{a}}$ \\
\hline $\begin{array}{l}\text { Defloor \& Grypdonk } \\
2005^{4}\end{array}$ & 1772 & Long-term care & 0.75 & $<14$ & 82 & 59 & 66 & 18 & $31^{\mathrm{a}}$ \\
\hline Jalali \& Rezaie $2005^{5}$ & 230 & Hospital & - & $\leq 16$ & 49 & 100 & 100 & 52 & $32^{a}$ \\
\hline Balzer et al. $2007^{6}$ & 542 & Hospital & - & $\leq 16$ & 76 & 75 & - & - & $4.5^{b}$ \\
\hline \multicolumn{10}{|l|}{$\begin{array}{l}\text { The modified Norton } \\
\text { scale }\end{array}$} \\
\hline $\begin{array}{l}\text { Ek } 1987 \text { (maximum } \\
\text { score } 32)^{7}\end{array}$ & 515 & Long-term care & - & $\leq 25$ & 51 & 65 & 13 & & $7.5^{\mathrm{a}}$ \\
\hline Ek (unpublished data) & 501 & Long-term care & - & $\leq 21$ & 69 & 69 & 32 & 91 & $10^{\mathrm{a}}$ \\
\hline $\begin{array}{l}\text { Gunningberg et al. } \\
1999 \text { (max. score } 28)^{8}\end{array}$ & 81 & Orthopaedic & - & $\leq 21$ & 71 & 44 & 35 & 78 & $30^{\mathrm{a}}$ \\
\hline \multicolumn{10}{|l|}{ The Braden scale } \\
\hline Bergstrom et al. $1987^{9}$ & $99 / 100$ & $\begin{array}{l}\text { Medical- } \\
\text { Surgical }\end{array}$ & - & $\leq 16$ & $100 / 100$ & $90 / 64$ & - & - & $7 / 9^{a}$ \\
\hline $\begin{array}{l}\text { Braden \& Bergstrom } \\
1994^{10}\end{array}$ & 102 & Nursing home & - & $\leq 18$ & 79 & 74 & 54 & 90 & $27^{\mathrm{a}}$ \\
\hline \multirow{3}{*}{$\begin{array}{l}\text { Bergstrom et al. } 1998 \\
11\end{array}$} & 843 & Tertiary care & - & $\leq 16$ & 38 & 92 & 31 & 94 & $8.5^{\mathrm{a}}$ \\
\hline & & $\begin{array}{l}\text { Medical- } \\
\text { surgical }\end{array}$ & - & $\leq 19$ & 50 & 82 & 17 & 96 & $7^{a}$ \\
\hline & & Long-term care & - & $\leq 18$ & 74 & 60 & 37 & 88 & $24^{\mathrm{a}}$ \\
\hline Halfens et al. $2000^{12}$ & 320 & Hospital & & $\leq 20$ & 73 & 70 & & & $15^{\mathrm{a}}$ \\
\hline $\begin{array}{l}\text { Schoonhoven et al. } \\
2002^{3}\end{array}$ & 2190 & Hospital & 0.55 & $\leq 16$ & 44 & 68 & 8 & 95 & $11^{\mathrm{a}}$ \\
\hline $\begin{array}{l}\text { Defloor \& Grypdonk } \\
2005^{4}\end{array}$ & 1772 & Long-term care & 0.77 & $<18$ & 83 & 58 & 66 & 17 & $31^{\mathrm{a}}$ \\
\hline Jalali \& Rezaie $2005^{5}$ & 320 & Hospital & - & $\leq 16$ & 53 & 100 & 100 & 58 & $2^{a}$ \\
\hline Balzer et al. $2007^{6}$ & 542 & Hospital & - & $\leq 19$ & 81 & 72 & - & - & $4.5^{b}$ \\
\hline Tannen et al. $2010^{13}$ & 1053 & Hospital & 0.86 & $\leq 18$ & 85 & 74 & - & - & $-{ }^{b}$ \\
\hline \multicolumn{10}{|l|}{ The RAPS scale } \\
\hline \multirow[t]{5}{*}{$\begin{array}{l}\text { Lindgren } \text { et al. } 2002 \\
(\text { maximum score } 39)\end{array}$} & 488 & $\begin{array}{l}\text { Hospital (total } \\
\text { sample) }\end{array}$ & - & $\leq 36$ & 57 & 58 & 14 & 92 & $12^{a}$ \\
\hline & 230 & Medical & - & $\leq 31$ & 75 & 70 & 19 & 97 & $9^{a}$ \\
\hline & 258 & Surgical & - & $\leq 38$ & 68 & 60 & 20 & 92 & $13^{a}$ \\
\hline & 76 & Infections & - & $\leq 31$ & 80 & 70 & 29 & 96 & $13^{\mathrm{a}}$ \\
\hline & 99 & Orthopaedic & - & $\leq 37$ & 70 & 70 & 41 & 88 & $23^{a}$ \\
\hline $\begin{array}{l}\text { Lindgren } 2002 \\
\text { (maximum score 35) } \\
\text { (unpublished data) }\end{array}$ & 488 & Hospital & - & $\leq 29$ & 78 & 70 & 32 & & $12^{\mathrm{a}}$ \\
\hline
\end{tabular}




\begin{tabular}{|c|c|c|}
\cline { 2 - 3 } \multicolumn{1}{c|}{} & Pressure ulcer & No pressure ulcer \\
\hline $\begin{array}{c}\text { Classified as 'at } \\
\text { risk' }\end{array}$ & $\mathrm{a}$ & $\mathrm{b}$ \\
\hline $\begin{array}{c}\text { Classified as } \\
\text { 'not at risk' }\end{array}$ & $\mathrm{c}$ & $\mathrm{d}$ \\
\hline
\end{tabular}

Figure 1. The template for calculation of sensitivity as a / $(a+c)$,

specificity as $d /(b+d)$, positive predictive value as $a /(a+b)$ and negative predictive value as $d /(c+d)$ 
Table 3. Characteristics of the participants

\begin{tabular}{|c|c|c|}
\hline & $\mathbf{n}=$ & $\%$ \\
\hline \multicolumn{3}{|l|}{ Age } \\
\hline$\geq 70$ & 216 & 62.0 \\
\hline $65-69$ & 38 & 11.1 \\
\hline$\leq 64$ & 89 & 25.9 \\
\hline \multicolumn{3}{|l|}{ Mobility } \\
\hline Chairfast & 38 & 11.0 \\
\hline Bedridden & 55 & 15.9 \\
\hline \multicolumn{3}{|l|}{ Incontinence } \\
\hline Urinary catheter user & 67 & 22.2 \\
\hline Urinary incontinence & 30 & 8.7 \\
\hline Faeces incontinence & 28 & 8.1 \\
\hline \multicolumn{3}{|l|}{ Nutrition } \\
\hline Food intake $3 / 4$ & 58 & 16.8 \\
\hline Food intake $\leq 1 / 2$ & 100 & 31.6 \\
\hline Intravenously & 29 & 4.0 \\
\hline Tube feeding & 14 & 8.3 \\
\hline \multicolumn{3}{|l|}{ Ward } \\
\hline Surgery & 85 & 24.6 \\
\hline Medicine & 136 & 39.3 \\
\hline Orthopaedic & 37 & 10.7 \\
\hline Oncology & 18 & 5.2 \\
\hline Rehabilitation & 70 & 20.2 \\
\hline
\end{tabular}


Table 4. The area under curve estimation of the Norton scale, Modified Norton scale, Braden scale and the RAPS scale and the sensitivity, specificity, PPV test, NPV test of the different risk assessment scales at various cut off points.

\begin{tabular}{|c|c|c|c|c|c|c|c|}
\hline Cut-off score & $\mathbf{n}$ & $\mathbf{A U C}$ & $\begin{array}{l}\text { Patients at } \\
\text { risk }(\%)\end{array}$ & $\begin{array}{l}\text { Sensitivity } \\
(\%)\end{array}$ & $\begin{array}{l}\text { Specificity } \\
(\%)\end{array}$ & PPV (\%) & $\begin{array}{l}\text { NPV } \\
(\%)\end{array}$ \\
\hline The Norton scale $^{a}$ & 344 & 0.787 & & & & & \\
\hline$\leq 13$ & & & 18.9 & 41.8 & 85.4 & 35.4 & 88.5 \\
\hline$\leq 14$ & & & 24.1 & 50.9 & 81.0 & 33.7 & 89.7 \\
\hline$\leq 15$ & & & 29.1 & 58.2 & 76.5 & 32.0 & 90.6 \\
\hline$\leq 16$ & & & 36.6 & 74.5 & 70.6 & 32.5 & 93.6 \\
\hline$\leq 17$ & & & 54.3 & 87.2 & 63.6 & 31.4 & 96.3 \\
\hline The Modified Norton ${ }^{b}$ & 342 & 0.791 & & & & & \\
\hline$\leq 19$ & & & 17.0 & 40.7 & 87.5 & 37.9 & 88.7 \\
\hline$\leq 20$ & & & 23.4 & 51.9 & 81.9 & 35.0 & 90.1 \\
\hline$\leq 21$ & & & 28.4 & 59.3 & 77.4 & 33.0 & 91.0 \\
\hline$\leq 22$ & & & 33.3 & 74.1 & 74.3 & 35.1 & 93.9 \\
\hline$\leq 23$ & & & 38.9 & 77.8 & 68.4 & 31.6 & 94.3 \\
\hline The Braden scale ${ }^{c}$ & 344 & 0.787 & & & & & \\
\hline$\leq 16$ & & & 25.3 & 54.5 & 80.3 & 34.5 & 90.3 \\
\hline$\leq 17$ & & & 29.4 & 61.8 & 76.8 & 33.7 & 91.4 \\
\hline$\leq 18$ & & & 34.0 & 74.5 & 73.7 & 35.0 & 93.8 \\
\hline$\leq 19$ & & & 40.7 & 81.8 & 67.1 & 32.1 & 95.1 \\
\hline$\leq 20$ & & & 50.3 & 87.3 & 56.7 & 27.7 & 95.9 \\
\hline The RAPS scale ${ }^{d}$ & 343 & 0.789 & & & & & \\
\hline$\leq 27$ & & & 29.2 & 63.0 & 77.2 & 34.0 & 91.8 \\
\hline$\leq 28$ & & & 32.7 & 74.1 & 75.1 & 35.7 & 93.9 \\
\hline$\leq 29$ & & & 37.6 & 77.8 & 69.9 & 32.6 & 94.4 \\
\hline$\leq 30$ & & & 42.6 & 83.3 & 65.1 & 30.8 & 95.4 \\
\hline$\leq 31$ & & & 49.3 & 85.2 & 57.4 & 27.2 & 95.4 \\
\hline
\end{tabular}

${ }^{\mathrm{a}}$ Norton et al. (1979); ${ }^{\mathrm{b}}$ Ek et al. (1991); ${ }^{\mathrm{c}}$ Braden \& Bergstrom (1987); ${ }^{\mathrm{d}}$ Lindgren et al. (2002) (without Salbumin) 